\title{
The Effects of Fillers on Polyurethane Resin-based Electrical Insulators
}

\author{
Ruy Alberto Corrêa Altafim ${ }^{\mathrm{a} *}$, Cacilda Ribeiro Murakami ${ }^{\mathrm{a}}$, Salvador Claro Netob, \\ Luiz, Carlos Ribeiro Araújo ${ }^{\mathrm{b}}$, Gilberto Orivaldo Chierice ${ }^{\mathrm{b}}$ \\ ${ }^{a}$ Department of Electrical Engineering \\ ${ }^{\mathrm{b}}$ São Carlos Institute of Chemistry, São Carlos School of Engineering - University of São Paulo \\ C.P. 359, 13566-590 São Carlos - SP, Brazil
}

Received: November 29, 2000; Revised: December 8, 2002

\begin{abstract}
The increasingly widespread use of polymeric insulators in vehicle distributors and transmission systems has led to an ongoing quest for quality and low costs. This quest has, in turn, resulted in improved performance and cost benefits, brought about by the use of new polymeric and composite resins. Occasionally, however, while some properties are improved, others may show a loss of optimal performance. Therefore, to understand the behavior of fillers, such as carbon black, silica and mica added to castor oil-derived polyurethane resins, several thermal, mechanical and electrical tests were conducted on samples and insulators produced specifically for this purpose, using these new materials. The results of these tests clearly demonstrated that this type of resin and its composites can be used to manufacture indoor electrical insulators and that the fillers analyzed in this study improve or maintain the characteristics of the pure resins.
\end{abstract}

Keywords: fillers, polyurethane resins, castor oil, and electric insulators

\section{Introduction}

Polymeric insulators are being used increasingly in distribution transmission eletric systems, representing from 60 to $70 \%$ of newly installed HV insulators in North America ${ }^{1}$. Non-ceramic composite insulator applications have expanded substantially owing to the advantages these insulators offer compared to the traditional ones of ceramic and glass. These advantages include light weight, higher mechanical strength to weight ratio, resistance to vandalism, superior performance in the presence of heavy pollution in wet conditions, and comparable or higher withstand voltage than porcelain or glass insulators. However, composite polymeric insulators also possess some disadvantages, such as superficial chemical changes caused by weathering and dry band arcing ${ }^{2}$, erosion and tracking, which may ultimately lead to failure of the insulators ${ }^{3}$, difficult to evaluate service life, unknown reliability, and difficult to detect faulty insulators ${ }^{4}$. To minimize or eliminate some of these disadvantages, a wide range of materials and formulations have been tested in the production of polymeric insulators, among them bisphenol epoxy, cycloaliphatic epoxy resins, ethylene propylene rubber (EPR), silicone rubber (SIR), and cycloaliphatic epoxy. An ethylene propylene monomer
(EPM) and SIR alloy was introduced in 1986, but it was subsequently changed to an ethylene propylene diene monomer (EPDM) and SIR compound in $1989^{5}$.

A major obstacle for these technological advances and for research with these materials in Brazil is that all the basic components are imported and their characteristics may be modified at any time. Castor oil-based polyurethane resins, which are produced with $100 \%$ Brazilian technology and possess excellent electrical and mechanical characteristics, therefore play a crucial role, as reported in previous papers $^{6,7}$.

These resins consist of polymerized Urethane, which was first synthesized by Wurtz in $1849^{8}$ and is a product of the chemical reaction between an isocyanate group and a hydroxyl, or:



In this polymerization, a compound containing two or more isocyanate groups per molecule reacts with a polyol, or a polyfunctional alcohol ${ }^{8}$. Despite the apparent simplic-

*e-mail: altafim@sel.eesc.sc.usp.br 
ity of this synthesis, any alterations in the polyol and prepolymer ratio $(-\mathrm{NCO} /-\mathrm{OH})$ cause substantial morphological changes in the resins' chains, leading to modifications in the material's mechanical properties, such as flexibility and rupture stress. The degree to which the polymer chains cross-link is controlled by the isocyanate group (-NHCOO-) existing in the pre-polymer and by the hydroxyl group existing in the polyol. Any increase in this degree can cause an increase in the thermal energy required to reach the critical temperature for softening, called the glass transition temperature ${ }^{9}$. The castor oil used in the synthesis of these resins, which derives from the seeds of the tropical "castor-oil plant" (Ricinus communis), plays a crucial role, since it contains $81-96 \%$ of the triglyceride of 12-hydroxyoleic (or ricinoleic) acid, triricinolein. The high concentration of this triglyceride in castor oil makes it almost chemically pure, allowing it to be treated as a natural polyol ${ }^{9}$. Several resins containing this oil, that may have similar chemical compositions ${ }^{8}$ but considerably different physical properties, are available in the Brazilian market.

The research reported on here investigated two of these commercial resins, which were synthesized in mass proportions of 1:1 and 1:1.75 at the São Carlos Institute of Chemistry, University of São Paulo, Brazil and were labeled RI 1 and RI 2, respectively ${ }^{7}$. Both resins were subjected to a total curing time of approximately $24 \mathrm{~h}$.

The resins' mechanical, electrical and thermal properties were improved by adding fillers such as carbon black, silica and mica to form composites. This study also analyzed electrical insulators made with these composites. Section 2 describes the experimental setup and the samples' compositions, while Sections 3 and 4 discuss the results of our investigation and our conclusions.

\section{Experimental}

\subsection{Samples}

Insulators and samples were produced by vacuum molding, using RI 1 and RI 2 resins doped with carbon black and silica having $\sim 0.05 \mathrm{~mm}$ sized particles, and composites containing $\sim 0.07 \mathrm{~mm}$ sized mica (cream colored) grains.

The carbon black and silica fillers, called $\mathrm{C} 1$, had a dual purpose: the former to provide protection against UV rays and the latter to reduce costs. The purpose of the mica filler, called $\mathrm{C} 2$, was to provide lamellar reinforcement and improve the material's dielectric, thermal and mechanical properties.

To facilitate the identification of the composites in this study, the names of the fillers were added to those of the resins; hence, the resins containing carbon black and silica were called RI $1 \mathrm{C} 1$ or RI $2 \mathrm{C} 1$, depending on the resin used (RI 1 or RI 2), while the resin containing mica was called RI $1 C 2$ or RI 2 C2.

\subsection{Thermal tests}

To determine the glass transition temperature, $\mathrm{Tg}$, and the initial decomposition temperature, $\mathrm{T}_{\mathrm{id}}$, of the resins and their composites, thermal tests were carried out using equipment set up according to the technical DMA (Dynamic Mechanical Analysis) and TG (Thermal Gravimetry) requirements. RI 1C1 samples (resin, silica and carbon black with mass and weight proportions of 10:2:0.2, respectively) and RI 1C2 samples (resin and mica in the proportions of 10:1, 10:2, 10:3 and 10:4, respectively) were prepared for these tests. All the samples for these tests were prepared as $3 \mathrm{~mm}$ thick $60 \times 12 \mathrm{~mm}$ rectangles.

The dynamic mechanical analysis was carried out using a DMA device (Du Pont Instruments, model 983) with a set frequency of $1 \mathrm{~Hz}$, a three-point flexural mode, amplitude of $0.50 \mathrm{~mm}$ and a heating rate of $5{ }^{\circ} \mathrm{C} / \mathrm{min}$. The thermal gravimetry analysis was performed using a TA device (Du Pont Instruments, model 951), with a heating rate of $10{ }^{\circ} \mathrm{C} / \mathrm{min}$, nitrogen atmosphere, $50 \mathrm{ml} / \mathrm{min}$ flux and a $10 \mathrm{mg}$ mass.

\subsection{Mechanical tests}

The mechanical tests to determine hardness, tensile strength and compressive strength were carried out on samples prepared according to the ASTM D229 standard ${ }^{10}$. Because preliminary results of the RI 2 resin and its composites showed an unfavorable thermal performance, only the RI 1C1 composites with a mass proportion of 10:2:0.2 and the RI 1C2 with mass proportions of 10:1; 10:2; 10:3 and 10:4 were subjected to mechanical tests.

The specimens were prepared in various shapes. For the hardness tests, the samples were $4.5 \mathrm{~mm}$ thick with $70 \times 50 \mathrm{~mm}$ rectangular sections. For the tensile strength tests, performed at a speed of $5.08 \mathrm{~mm} / \mathrm{min}$, the samples had to conform to standardized type II specimens ${ }^{10}$. And for the compressive stress tests, performed at a speed of $1.30 \mathrm{~mm} / \mathrm{min}$, the samples were shaped into $12.7 \mathrm{~mm}$ diameter, $25.4 \mathrm{~mm}$ long cylinders.

\subsection{Electrical tests}

For the electrical tests, insulator samples were prepared from the RI 1 and RI 2 resins and its composites RI 1C1 and RI 2C1 with a mass proportion of 10:2:0.2 (resin, silica and carbon black, respectively) and, from the RI $1 \mathrm{C} 2$ and RI $2 \mathrm{C} 2$ with a mass proportion of 10:2 (resin and mica, respectively). Figure 1 shows one of the tested insulators. These tests were performed applying an increasing alternating voltage of $60 \mathrm{~Hz}$ at a uniform rate of $500 \mathrm{~V} / \mathrm{s}$ on the insulator samples until its breakdown occurred. The alternating voltages were generated and measured using a High Voltage KIT (Haefely Trench-100 kV). 




Figure 1. Insulator of the indoor type manufactured with polyurethane resin.

\section{Results}

\subsection{Thermal tests}

Tables 1 and 2 and Fig. $2 \mathrm{a}$ and $2 \mathrm{~b}$ show the results of the thermal tests or the glass transition temperature, Tg and initial decomposition temperature, $\mathrm{T}_{\mathrm{id}}$. For the RI 2 resin and its RI 2C1 composite, the glass transition temperatures were not determined by filling the cell of the DMA apparatus with liquid nitrogen, because these temperatures were not part of the purpose of this study, which focused solely on polymeric insulators for use in tropical temperatures.

Figure 2 shows that, unfortunately, the variation of the proportion of mica added to the resins failed to influence the thermal characteristics. However, the $\mathrm{Tg}$ and $\mathrm{T}_{\text {id }}$ values of these composites with mica were found to be similar to those of pure resins. These results suggest that the use of these composites in manufactured products may substantially reduce their costs. Another important result was evidenced by the thermal tests performed with the DMA apparatus, which revealed alterations in the mechanical characteristics of the resins containing varied amounts of mica filler. These alterations consisted of an increase in the moduli of storage elasticity $\left(E^{\prime}\right)$ values and a loss of ( $E$ ”) values of these materials at an ambient temperature of $29.9{ }^{\circ} \mathrm{C}$, as indicated in Table 2.

\subsection{Mechanical tests}

\subsubsection{Hardness tests, Shore D scale}

Table 3 shows the results of the hardness tests on the Shore D scale for rigid samples measured at five different points in each sample. As can be seen, the hardness of the
Table 1. Results of the thermal tests. Glass transition temperature, $\mathrm{Tg}$ and initial decomposition temperature, $\mathrm{T}_{\mathrm{id}}$.

\begin{tabular}{ccc}
\hline Type of Material & $\mathrm{Tg}\left({ }^{\circ} \mathrm{C}\right)$ & $\mathrm{T}_{\text {id }}\left({ }^{\circ} \mathrm{C}\right)$ \\
\hline Resin RI 1 (10:0) & 70.00 & 260.80 \\
Resin RI 1C1 (10:2:0.2) & 69.00 & 265.90 \\
Resin RI 2 (10:0) & - & 255.80 \\
Resin RI 2C1 (10:2:0.2) & - & 259.60 \\
Resin RI 1 C2 (10:1) & 71.00 & 257.10 \\
Resin RI 1 C2 (10:2) & 70.00 & 262.20 \\
Resin RI 1 C2 (10:3) & 69.00 & 262.00 \\
Resin RI 1 C2 (10:4) & 68.00 & 259.20 \\
\hline
\end{tabular}



(a)

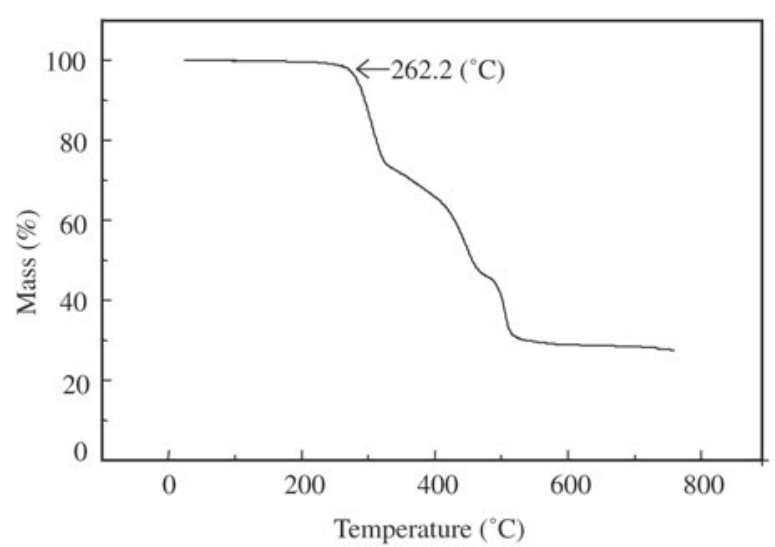

(b)

Figure 2. Curves of the characteristics: (a) Tg of the RI 1 resin with different proportions of mica filler; (b) $\mathrm{T}_{\mathrm{id}}$ of the RI 1C2 resin with a mass proportion of 10:2.

RI 1 resin containing mica filler in varying mass proportions was very similar to that of the pure RI 1 resin. In contrast, however, the RI 2 resin and its RI $2 \mathrm{C} 1$ composite showed only half the hardness of the RI 1 resin. 
Table 2. Variation of the E' and E" moduli of the RI 1 resin with varying proportions of mica.

\begin{tabular}{lccccc}
\hline $\begin{array}{l}\text { Mechanical } \\
\text { characteristics }\end{array}$ & $\begin{array}{c}\text { RI 1 (10:0) } \\
\text { (without filter) }\end{array}$ & $\begin{array}{c}\text { RI 1 C2 } \\
(10: 1)\end{array}$ & $\begin{array}{c}\text { RI 1 C2 } \\
(10: 2)\end{array}$ & $\begin{array}{c}\text { RI 1 C2 } \\
(10: 3)\end{array}$ & $\begin{array}{c}\text { RI 1 C2 } \\
(10: 4)\end{array}$ \\
\hline$E^{\prime}(\mathrm{GPa})$ & 1.67 & 1.68 & 1.83 & 2.63 & 3.04 \\
$E^{\prime}$ (MPa) & 78.45 & 99.29 & 111.20 & 140.50 & 162.10 \\
\hline
\end{tabular}

Table 3. Hardness test results on the Shore D scale.

\begin{tabular}{lcc}
\hline $\begin{array}{l}\text { Type of } \\
\text { Material }\end{array}$ & $\begin{array}{c}\text { Hardness } \\
\text { (Shore D) }\end{array}$ & $\begin{array}{c}\text { Standard } \\
\text { Deviation }\end{array}$ \\
\hline Resin RI 1 & 79.40 & 0.55 \\
Resin RI 1C1 & 80.80 & 0.45 \\
Resin RI 1C2 & 79.40 & 0.55 \\
Resin RI 2 & 45.00 & 0.71 \\
Resin RI 2C1 & 48.00 & 0.55 \\
\hline
\end{tabular}

\subsubsection{Tensile strength tests.}

Table 4 shows that the RI 1 resin and its composites, RI $1 \mathrm{C} 1$ and RI 1C2, presented a higher tensile strength than the $\mathrm{RI} 2$ resin and its composite $\mathrm{RI} 2 \mathrm{C} 1$ used in the production of insulators.

\subsubsection{Compressive strength tests.}

Table 5 lists the results of the compressive strength tests.

Table 4. Tensile strength test results.

\begin{tabular}{lcc}
\hline $\begin{array}{l}\text { Type of } \\
\text { Material }\end{array}$ & $\begin{array}{c}\text { Tensile strength } \\
(\mathrm{MPa})\end{array}$ & $\begin{array}{c}\text { Standard } \\
\text { Deviation }\end{array}$ \\
\hline Resin RI 1 & 24.45 & 0.23 \\
Resin RI 1C1 & 24.16 & 0.54 \\
Resin RI 1C2 & 23.64 & 1.58 \\
Resin RI 2 & 5.66 & 0.64 \\
Resin RI 2C1 & 5.78 & 0.43 \\
\hline
\end{tabular}

Table 5. Compressive strength test results.

\begin{tabular}{lcc}
\hline $\begin{array}{l}\text { Type of } \\
\text { Material }\end{array}$ & $\begin{array}{c}\text { Compressive strength } \\
\text { (MPa) }\end{array}$ & $\begin{array}{c}\text { Standard } \\
\text { Deviation }\end{array}$ \\
\hline Resin RI 1 & 193.23 & 34.32 \\
Resin RI 1C1 & 257.87 & 51.04 \\
Resin RI 1C2 & 279.98 & 39.40 \\
Resin RI 2 & 90.61 & 12.82 \\
Resin RI 2C1 & 90.07 & 3.91 \\
\hline
\end{tabular}

Table 6. Voltage at which the polymeric insulators underwent external flashover.

\begin{tabular}{ccc}
\hline $\begin{array}{c}\text { Insulators } \\
\text { manufactured from } \\
\text { resins and composites }\end{array}$ & $\begin{array}{c}\text { RMS Voltage } \\
\text { of external flashover } \\
(\mathrm{kV})\end{array}$ & $\begin{array}{c}\text { Standard } \\
\text { Deviation } \\
\text { (RMS Voltage) }\end{array}$ \\
\hline RI 1 & 84.78 & 0.25 \\
RI 2 & 84.98 & 0.11 \\
RI 1C1 & 83.65 & 0.36 \\
RI 2C1 & 85.11 & 0.78 \\
RI 1C2 & 84.58 & 0.11 \\
RI 2C2 & 85.71 & 0.02 \\
\hline
\end{tabular}
and its RI 1C1 and RI 1C2 composites could not be measured with the apparatus available in our laboratory. However, the values given here are the peaks of compressive strength.

\subsection{Electrical tests}

Because the electric tests were performed on insulator samples and all the breakdowns occurred in the air rather than inside the polymeric insulator samples, the voltages listed in Table 6 are the withstand RMS voltages. The breakdown voltages of the polymeric insulators tested were higher than the ones shown here. According to Diesendorf ${ }^{11}$, these voltages are not normally determined for non-restoring insulators.

\section{Conclusions}

The values of the glass transition temperature, $\mathrm{Tg}$, and the initial decomposition temperature, $\mathrm{T}_{\mathrm{id}}$, listed in Table 1 allow us to conclude that the RI 2 resin and its composites RI $2 \mathrm{C} 1$ and RI $2 \mathrm{C} 2$ are potentially applicable in the manufacture of indoor products such as insulators. The RI 1 resin and its composites RI $1 \mathrm{C} 1$ and RI 1C2, on the other hand, can be used for both indoor and outdoor applications up to approximately $70{ }^{\circ} \mathrm{C}$.

The silica and carbon black fillers added in these polyurethane resins did not significantly alter the thermal and mechanical properties of the composites compared to those of the pure resins, as shown in Tables 1, 3, 4 and 5. The mica filler, moreover, was found not to alter the composite's glass transition temperature.

The the decomposition temperature, tensile strength, compressive strength and hardness values showed no sig- 
nificant alterations, as illustrated in Tables 1, 3, 4 and 5 and Fig. 2. Table 2, however, reveals that the polymer's viscous elastic characteristics changed according to the mass proportion of mica, showing increased moduli of storage elasticity and loss. Further experimentation is therefore necessary to analyze the influence and importance of mica in electrical insulation applications.

With regard to the electrical tests, only the ultimate alternating voltage was determined because flashover occurred in the air and not inside the insulators. This RMS voltage presented values in excess of $80 \mathrm{kV}$, with a peak voltage above $113 \mathrm{kV}$. These values are extremely high for distribution line insulators, indicating that these resins and their composites have a good potential for such applications. However, further electrical tests should be performed, including impulse voltage tests.

Another benefit resulting from the use of mineral fillers, i.e., lower polymer insulator production costs, is shown in Table 6, which also demonstrates that the different fillers in the proportions used in this study did not interfere in the material's electrical behavior.

\section{Acknowledgments}

This study was made possible with the help and cooperation of the Institute of Chemistry of the University of São Paulo at São Carlos and the financial support of FAPESP, a Brazilian research funding institution.

\section{References}

1. Zhao, T.; Bernstorf, L. Aging Tests of Polymeric Housing Materials for Non-Ceramic Insulators, IEEE Electrical Insulations Magazine, v. 14, n. 2, p. 26-33, 1998.

2. Kim, S.H.; Cherney E.A.; Hacham, R.; Rutherford, K.G. Chemical Changes at the Surface of RTV Silicone Rubber Coatings on Insulators During Dry Band Arcing, IEEE Transactions DEI, v. 1, p. 106-123, 1994.

3. Gorur, R.S.; Cherney, E.A.; Hackam, R.; Orbeck, T. The
Electrical Performance of Polymeric Insulating Materials Under Accelerated Aging in Fog Chamber, IEEE Transactions PD, v. 3, p. 1157-1164, 1988.

4. Kindersberg, J.; Scutz, A.; Karner, H.C.; Huir, R.V.D. Service Performance, Material Design and Applications of Composite Insulators With Silicone Rubber Housings, CIGRE 33-303, p. 1-5, 1996.

5. Hackam, R. Outdoor HV Composite polymeric Insulators-Review, IEEE Transactions on Dielectrics and Electrical Insulation, v. 6, n. 5, p. 557-585, October/1999.

6. Murakami, C.R.; Altafim, R.A.C.; Araújo, L.C.R.; Claro Neto, S., Chierice, G.O., Use of polyurethane resins derived from castor oil in the production of polymeric insulators - Part I, $8^{\text {th }}$ Regional Latin American Meeting CIGRE, $15^{\text {th }}$ Study Committee, Ciudad del Este, Paraguay, March/1999.

7. Altafim, R.A.C.; Murakami, C.R.; Araújo, L.C.R.; Claro Neto, S.; Chierice, G.O. Polyurethane resins derived from castor oil for the fabrication of polymeric insulatorsPart II, 1999 Conference on Electrical Insulation and Dielectric Phenomena, IEEE Dielectrics and Electrical Insulation Society, Austin, Texas, October/1999.

8. Claro Neto, S. Physical and chemical characterization of castor-oil derived polyurethanes used in bone implants, Doctoral Thesis, São Carlos Institute of Chemistry, University of São Paulo, São Carlos, Brazil, 1997.

9. Araújo, L.C.R. Chemical, thermal and mechanical characterization of polyurethane elastomers based on plant oil derivatives, Dissertation for Master's degree, Institute of Chemistry of São Carlos, University of São Paulo, São Carlos, Brazil, 1992.

10. American Society for Testing and Materials, ASTM D229 - Standard Test Method for Rigid Sheet and Plate Materials used in Electrical Insulation, West Conshohocken, 1996.

11. Diesendorf, W. Insulation Co-ordination in High Voltage Electric Power Systems, Butterworth \& Co. (Publishers) Ltd., London, 1974. 